\title{
A ORDENAÇÃO DE LOCUÇÕES ADVERBIAIS DE TEMPO EM CARTAS JESUÍTICAS DOS SÉCULOS XVI E XVII
}

\section{RESUMO}

Neste trabalho, discutimos as tendências de ordenação das locuções adverbiais de tempo em cartas escritas por jesuítas nos séculos XVI e XVII, bem como apresentamos algumas das motivações para seu posicionamento na oração por meio de uma análise estrutural e discursivo-pragmática. Seguimos os pressupostos teóricos do funcionalismo norte-americano, considerando relevante a relação entre forma e função no discurso. Buscamos (a) verificar padrões de posicionamento na oração, (b) analisar fatores que motivam as diferentes posições dessas locuções e (c) comparar os resultados com outras sincronias do português, avaliando em que medida eles podem apontar para indícios de mudança linguística.

PALAVRAS-ChAVE: locuções adverbiais de tempo, funcionalismo, ordenação, história da língua portuguesa.

\section{INTRODUÇão}

Este artigo segue a tendência de estudos baseados no uso relativos a advérbios e locuções adverbiais temporais, buscando mapear sua ordenação e investigar quais fatores estruturais e discursivo-pragmáticos podem ser determinantes para seu posicionamento. Focalizamos aqui as locuções adverbiais de tempo (tais como "naquelle mesmo instante", "neste mesmo tempo", "ainda agora" e "tres ou quatro annos"), coletadas e analisadas a partir de cartas jesuíticas dos séculos XVI e

Mestrando em Linguística pela Universidade Federal do Rio de Janeiro (UFRJ), Rio de Janeiro, Rio de Janeiro, Brasil. E-mail: dennisscastanheira@gmail.com

** Doutora em Linguística pela Universidade Federal do Rio de Janeiro (UFRJ), Rio de Janeiro, Rio de Janeiro, Brasil. Professora associada da Universidade Federal do Rio de Janeiro (UFRJ), Rio de Janeiro, Rio de Janeiro, Brasil. E-mail: mmcezario@gmail.com. 
XVII, com o objetivo de (a) verificarmos padrões de posicionamento na oração, (b) analisarmos fatores motivadores das diferentes posições dessas locuções e (c) comparar os resultados com outras sincronias do português, avaliando em que medida eles podem apontar para indícios de mudança linguística.

Como fundamentação teórica, adotamos uma abordagem funcionalista. O funcionalismo norte-americano atualmente enquadrase numa linha mais ampla denominada Linguística Funcional Centrada no Uso (KEMMER; BARLOW, 1999; BYBEE, 2010; MARTELOTTA, 2011). Pautando-se em situações comunicativas reais, essa teoria considera fatores históricos, cognitivos e contextuais para explicar o uso da língua. Seus estudos são amplos e englobam desde aspectos da mudança linguística até a apresentação de redes construcionais (TRAUGOTT; TROUSDALE, 2013), além de proporcionarem aplicações para o ensino de língua portuguesa (CEZARIO; FURTADO, 2013). Essa corrente teórica considera, então, que a gramática emerge das situações de uso e, portanto, o pesquisador precisa considerar a relação entre aspectos formais e contextuais em sua análise.

Desde a publicação de Martelotta (1994) e a consequente constatação da importância de fatores discursivo-pragmáticos para a ordenação dos circunstanciadores temporais na oração, os advérbios e locuções adverbiais de tempo ganharam especial destaque na literatura linguística funcionalista ( ANDRADE, 2005; MACHADO, 2012; SOARES, 2012). Essas investigações seguem uma abordagem metodológica semelhante: mapear o posicionamento do adverbial ${ }^{1}$, identificando suas tendências e suas respectivas motivações.

Por meio de uma abordagem (sócio) funcionalista, as pesquisas sobre o comportamento dos circunstanciadores demonstraram especial produtividade em relação à análise de distintas sincronias do português. Costa Nunes (2014), sob aporte cognitivo-funcional, estabeleceu um estudo diacrônico sobre a construção Xmente temporal e aspectual, destacando principalmente mudanças na sua ordenação. Seu objeto de investigação passou, ao longo da história do português, da posição majoritariamente pré-verbal ao posicionamento pós-verbal. Já Castanheira e Cezario (2014), numa abordagem 
funcionalista, destacaram o português do século XIX para detectar as motivações para ordenação das locuções adverbiais temporais. Também investigando as construções de valor temporal, há, por exemplo, o trabalho de Soares (2012), com corpus do português escrito contemporâneo.

Apesar de haver pesquisas sobre o posicionamento das locuções adverbais de tempo em distintas sincronias, não há investigações relacionadas aos séculos XVI e XVII com a orientação teóricometodológica apresentada aqui. Estudos diversos demonstraram ser produtiva a pesquisa sobre adverbiais temporais relacionadas a cartas, tais como, Machado (2012), Costa Nunes (2014) e Castanheira e Cezario (2014). Optamos, então, por adotar esse gênero textual para coleta de nossa amostra.

A partir de fatores que já demonstraram motivar a ordenação da locução em outros estudos (MACHADO, 2012; CASTANHEIRA; CEZARIO, 2014), observamos dois fatores: papel discursivo-textual e ordem da oração, além do posicionamento da locução. A partir dos aspectos que observaremos em nosso objeto de estudo, formulamos as seguintes hipóteses:

a) há uma posição prototípica para as locuções na oração. Diante de resultados de pesquisas anteriores (SOARES, 2012; CASTANHEIRA; CEZARIO, 2014), acreditamos que elas devam ocupar as posições marginais da cláusula;

b) o papel discursivo-textual do adverbial influencia a posição de seus sintagmas. Postulamos, a partir do estudo de Paiva (2008), que, caso a locução possua uma função discursiva mais relacionada ao contexto em que se insere-como retomar algo no discurso ou introduzir um assunto - haverá mais ocorrências à esquerda da oração. Por outro lado, quando sua função for apenas atribuir coordenadas temporais, ou seja, quando o escopo da locução adverbial for restrito à cláusula, haverá mais locuções em posições à direita;

c) as locuções tenderão a ocupar a margem esquerda da oração quando o sujeito estiver em posicionamento pós-verbal (VS); e tenderão a ocupar as posições pós-verbais quando o sujeito assumir outras posições na oração (SV, V e S(PR)V). 


\section{Metodologia e corpus}

Coletamos e analisamos 302 orações com locuções adverbiais de tempo em cartas jesuíticas escritas nos séculos XVI e XVII, procurando manter semelhante quantitativo entre as sincronias para que fosse possível estabelecer uma discussão comparativa. Nossos dados foram retirados dos livros Cartas avulsas e Cartas do Padre António Vieira, que reúnem coletâneas de cartas oriundas dos séculos XVI e XVII e contêm notas explicativas e contextualização desses períodos da história do Brasil. Utilizamos o programa estatístico Statistical Package for the Social Scienses (SPSS) para que obtivéssemos frequência e cruzamento dos fatores analisados. A linha teórica adotada é a descrita acima: o funcionalismo norte-americano.

Assim como aponta Bakhtin (2003), os gêneros textuais constituem práticas sócio-históricas relativamente estáveis e ligadas a ações sociais necessárias às situações comunicativas. Dessa forma, o gênero está intrinsecamente conectado aos contextos socioculturais em que se insere. Marcuschi (2002) aponta que antes de existirem escritas alfabéticas a quantidade de gêneros textuais era bem menor, já que os povos da época possuíam apenas a oralidade como forma de comunicação. O gênero, então, é uma junção de aspectos funcionais, sociais, comunicativos e estruturais.

Segundo Bakhtin (2003), é preciso levar em consideração os seguintes elementos para se classificar um gênero: conteúdo temático (assunto), plano composicional (estrutura formal) e estilo. Tais fatores estão relacionados entre si e são determinados em função das especificidades de cada situação de comunicação.

Determinados gêneros podem ser característicos de um domínio discursivo específico. Esse termo caracteriza, segundo Marcuschi (2002), uma espécie de esfera de produção discursiva ou atividade humana. Nessa, encontram-se os domínios jornalístico e religioso, por exemplo. No domínio religioso, há alguns gêneros prototípicos, como as ladainhas e as novenas. Escritas por jesuítas, as cartas por nós analisadas parecem pertencer tanto à esfera religiosa, como a um domínio interpessoal. Tradicionalmente, as cartas, de uma maneira ampla, enquadram-se no segundo domínio, assim como exemplifica Marcuschi (2012) por meio de cartas pessoais e de comércio. 
Segundo Londoño (2002), no entanto, as cartas jesuíticas tinham como objetivo tanto abordar a rotina das missões com informações práticas sobre a vivência nas colônias portuguesas, como utilizar um discurso religioso para enaltecer os avanços da glória divina nas missões. Um estudo dessas cartas, segundo o autor, aponta para uma multiplicidade de sentidos. Pautando-se nisso, acreditamos que elas possam transitar entre os dois domínios, constituindo uma amostra bastante rica para análise.

Assim como postulam Bakhtin (2003) e Marcuschi (2012), ao estudarmos um gênero textual, descobrimos sobre o funcionamento de uma determinada sociedade num dado momento. As cartas jesuíticas retratam o cotidiano das companhias de Jesus nas colônias portuguesas e por meio delas é possível estabelecermos uma reconstituição da vivência e construção da memória desse grupo no Brasil (LONDOÑO, 2002).

Em relação à forma, as cartas jesuíticas apresentam estrutura típica de cartas, com formas de tratamento introdutórias, corpo e fecho, assim como o exemplo a seguir:

\section{CARTA VIII}

Ao Marquês de Niza

\section{7 - Setembro 26}

Ex.Sr. - Pelas cartas que em outros navios haverão chegado, terá V. Ex. entendido como S. M., que Deus guarde, me manda a essa corte a servir nela alguns dias a V. Ex.â, circunstância que só me pudera facilitar a obediência de tão trabalhosas jornadas, como eu tenho experimentado estas.

A presente foi a mais cheia de perigos e infortúnios que jamais se padeceu nesta carreira, faltando-nos só a morte, mas não os riscos dela, que quási não houve dia sem susto, cuja relação reservo para a presença: alfim a cabo de trinta e nove dias de viagem, havendo-nos tomado os dunkerqueses um patacho francês, que me havia de lançar no Havre de Grâce, cheguei em uma nau inglesa ao,porto de Douvres, de onde logo tratei de atravessar a Calais, mas achei estar a cidade impedida de peste, com que foi necessário dilatar e mudar o caminho. E, porque o dinheiro que trouxe comigo era pouco, e aqui tem grandíssimas quebras, nem achar mercador que rrio desse, foi força ir negociá-lo a Londres, onde vim pela posta, trazendo co- 
migo as cartas de todas as embaixadas, para de aqui as encaminhar, como faço, por mão do senhor embaixador de França, debaixo de cujos maços irão seguras, reservando somente aquelas que não posso apartar de mim. Amanhã parto outra vez a Douvres a embarcar-me, e procurarei com toda a brevidade achar-me aos pés de "V. Ex.a. Guarde Deus a V- Ex.a muitos anos como desejo. Londres, e Setembro 26 de 647. Vão também os maços das senhoras Marqueza e Condessa, e outro para o senhor Residente, a quem beijo a mão.

Antônio Vieira.

$\mathrm{Na}$ carta acima, observamos um tipo de cabeçalho com a forma de tratamento "Ex. Sr" seguida do corpo com seu respectivo conteúdo e um fecho estimando que seja proteção, além de uma assinatura. Outros tipos de cartas também englobam essa estrutura, assim como aponta Machado (2012), por exemplo.

\section{AnÁlise}

\subsection{ORdenaÇÃo}

Para iniciarmos nossa análise, apresentaremos as quatro possibilidades para o posicionamento das locuções adverbiais de tempo na oração. Após cada uma delas, elencaremos dois exemplos, cada um proveniente de uma sincronia analisada. Consideramos as seguintes posições:

(a)

Margem esquerda: o adverbial está no início da oração.

(1)

"Um dia com grande pressa e efficacia pediu o Bautismo, o qual bautizou o padre Navarro, e dahi a 7 ou 8 dias adoeceu de câmara" (Carta V-Século XVI)

"O mesmo cuidado houve da nossa parte em fazer ajuntar os índios, para o edifício de uma fortaleza que, no mesmo tempo, se levantou na barra." (Carta I - Ao Geral da Companhia de Jesus - Século XVII) 
(b)

Margem Direita: a locução adverbial encontra-se no fim da oração.

(3)

"Digo-lhe missa todos os domingos e festas." (Carta XIII - Século XVI)

(4)

"Tanto que, o sol saiu em 10 de Maio, julgando os holandeses, da muita quietação da cidade, estar sem defensores, deliberaram-se a entrar nela. (Carta I - Ao Geral da Companhia de Jesus - Século XVII)

(c)

Pré-verbal não inicial: o adverbial ocorre antes do verbo, porém não está em posição de início de oração.

"O povo gentio ao principio nos dava pouco credito e lhe parecia que lhe mentiamos e o enganávamos, porque os clérigos e também os leigos ministros de Satanaz, que ao principio a esta terra vieram, lhes pregavam e fadavam por interesse de seus abomináveis resgates." (Carta $\mathrm{V}$ - Século XVI)

(6)

"Visto o que, respondeu o capitão que, enquanto ao sobrinho, devia de morrer na briga, porque o não tinha preso, e ao segundo, que não havia na terra outro refresco senão o que nos dois dias antecedentes tinham experimentado, e com êle estava aparelhado para os receber a qualquer hora." (Carta I - Ao Geral da Companhia de Jesus - Século XVII)

(d)

Pós-verbal não final: a locução apresenta-se após o verbo, contudo não ocupa o fim da oração.

"Tal aconteceu uma das noites passadas em suas aldeias que parecia o dia de juízo" (Carta I - Século XVI) 
(8)

"Entrou na Companhia no ano de 1556, de 15 anos de idade; viveu nela 60, e faleceu de 75, aos 27 de Janeiro do ano de 1625." (Carta I - Ao Geral da Companhia de Jesus - Século XVII)

As tabelas a seguir demonstram a frequência nos usos de locuções temporais nas duas sincronias observadas:

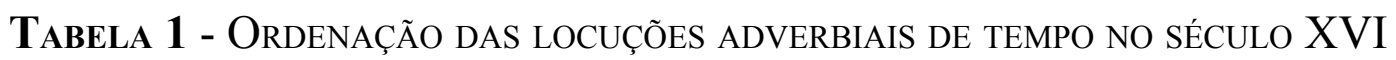

\begin{tabular}{l|c|c}
\hline OrdenaÇão & OCORRÊnCIAS & PerCENTUAL (\%) \\
\hline Margem Esquerda & 62 & 40,8 \\
\hline Margem Direita & 60 & 39,5 \\
\hline Pré-verbal não inicial & 4 & 2,6 \\
\hline Pós-verbal não final & 26 & 17,1 \\
\hline Total & 152 & 100,0 \\
\hline
\end{tabular}

Fonte: Elaborado pelos autores.

De acordo com a hipótese apresentada, o adverbial tenderia a ocorrer principalmente nas margens da oração. Ao observarmos a tabela 1, percebemos que essa tendência se confirmou, já que tivemos $40,8 \%$ dos dados em margem esquerda e $39,5 \%$ em margem direita, ou seja, quase $80 \%$ dos dados encontrados estão nas margens. Nas demais posições, obtivemos percentuais bem menores, a saber: $17,1 \%$ em posições posteriores ao verbo (excetuando margem direita) e 2,6\% em posições anteriores ao verbo e não iniciais.

TABELA 2 - ORdenAÇ̃̃o dAS LOCUÇÕES TEMPORAIS NO SÉCULO XVII

\begin{tabular}{l|c|c}
\hline OrdenaÇão & OCORRÊnCIAS & PERCENTUAL (\%) \\
\hline Margem Esquerda & 59 & 39,3 \\
\hline Margem Direita & 60 & 40,0 \\
\hline Pré-verbal não inicial & 6 & 4,0 \\
\hline Pós-verbal não final & 25 & 16,7 \\
\hline Total & 150 & 100,0 \\
\hline
\end{tabular}

Fonte: Elaborado pelos autores. 
$\mathrm{Na}$ tabela 2, observamos que as locuções ocorreram majoritariamente nas margens da oração, conforme nossa hipótese, já que obtivemos mais ocorrências em margem direita $(40 \%$ dos dados) e margem esquerda (39,3\% dos adverbiais temporais), o que soma também cerca de $80 \%$ dos dados encontrados nesse século. As demais posições representaram $16,7 \%$ em ocorrências pós-verbais não finais e $4 \%$ em casos da locução antes do verbo, porém fora da margem.

Se compararmos ambas as sincronias, veremos que, quanto ao nosso postulado de maior frequência nas margens da oração, houve uma manutenção de uso. Estabelecendo uma comparação com outras sincronias do português, observamos que, nos séculos XVIII, XIX e no português contemporâneo, também houve a mesma tendência de uso das locuções nas margens da oração (MACHADO, 2012; SOARES, 2012). Nos estudos de Machado (2012) e de Castanheira e Cezario (2014), com base em cartas dos séculos XVIII e XIX, entretanto, a maior parte das locuções adverbiais estiveram em margem direita.

Esse resultado está de acordo com as tendências gerais de mudança de posicionamento de advérbios na língua portuguesa, em que houve uma ocupação predominante da posição pós-verbal a partir do século XVIII, sendo posicionamento obrigatório, inclusive de alguns advérbios, como "bem" e "mal" (MARTELOTTA, 2004; MARTELOTTA; VLCEK, 2006).

$\mathrm{Na}$ visão funcionalista, forma e função possuem uma íntima relação. Sendo assim, as posições assumidas pela locução adverbial nos contextos em que ela se insere são motivadas. Essas podem ter cunho sintático ou discursivo pragmático. Por isso, efetuamos o cruzamento entre a ordenação do adverbial e possíveis fatores determinantes: função discursiva, ordem da oração e continuidade tópica.

\subsection{FUNÇÃO DISCURSIVA}

Segundo a corrente funcionalista, a ordenação de palavras é em geral motivada por fatores, sobretudo, de ordem discursiva e pragmática. Então, cabe-nos verificar as razões pelas quais ora os usuários optam pela margem esquerda, ora pela direita e ora por outras 
posições. Aqui verificaremos a função da locução adverbial tendo em vista o seu papel no texto.

Por muitos anos, a literatura considerou que os adverbiais temporais e locativos tinham como papel textual apenas atribuir tempo ou lugar. Paiva (2008), no entanto, elencou algumas possibilidades de funções outras que essas categorias podem assumir no discurso. A partir de seu trabalho, investigações adotaram parcial ou totalmente sua classificação. Aqui, seguimos a mesma adaptação de Castanheira e Cezario (2014), a saber:

(a)

Atribuidor de coordenadas temporais: a locução tem como função apenas designar tempo ao evento.

"Comtudo isso porque chovia muito e iamos muito molhados, recolhemo-nos a outra Casa a enxugar, e dahi a pouco vieram com grande fúria com espadas e outras armas contra nós;" (Carta IV - Século XVI)

“Também falei no a casa do Príncipe, que se lhe dará muito brevemente, e também S. M. aprovou; estão três nomeados, que são os condes de Vila Nova, e de Vai de Reis e Fernão Teles." (Carta XLIX - A Francisco de Sousa Coutinho - Século XVII).

Em ambos os exemplos, as locuções adverbiais atribuem tempo ao evento, só designando quando foram atacados (em (9)) e quando ocorrerá o que está sendo narrado (em (10)). Ou seja, não elas não exercem outro papel discursivo-textual.

(b)

Retomada anafórica: o adverbial retoma algo já enunciado no discurso.

"Todos os domingos fazemos procissão dirigindo-nos a certas ermidas que se fizeram para as peregrinações pias, e outras devoções semelhantes: occupo- me outrosim no mesmo dia em ordenar que se casem os que não são casados, os quaes todos tinham por concubinas as próprias escravas." (Carta I - Século XVI) 
"E, sobre tudo, pagarmos aos holandeses em dez anos é termos todo este tempo em nossa mão um penhor e caução sua, para melhor nos guardarem o que nos prometerem. Finalmente, muito mais nos tomaram os holandeses nos mares do Brasil, nestes seis meses, do que nós lhes prometemos em todos os dez anos." (Carta XLVII - Ao Marquês de Niza - Século XVII)

Em (11), "no mesmo dia" retoma "todos os domingos" e, em (12), "em todos os dez anos" estabelece uma retomada em relação à locução "em dez anos", isto é, ambos têm como papel retomar algo já proferido no discurso.

(c)

Sequência temporal: a locução estabelece uma sequência de tempo com outro adverbial.

"A's segundas e terças-feiras, visito três ou quatro aldêas; ás quartas e quintas duas ou três das aldêas mais distantes, e á sexta feira volto á cidade para fazer a exhortação a uma companhia de disciplinantes cuja devoção vai em muito augmento por graça de Deus, principalmente agora na quaresma, o que serve de exemplo edificante aos mais." (Carta I - Século XVI)

"Eu tive carta do Brasil, vinda no último aviso, em que me dizem que a nossa armada se ficava esperando por horas; que Sigismundo queimara tudo o que tinha em Taparica, que vinha a ser pouco mais que as barracas dos soldados; e que em 13 de Dezembro se embarcara, e em 15 saíra pela barra fora com catorze navios, oito grandes e seis pequenos, bem desigual poder para a nossa armada se lá o achara: mas Deus que ordena tudo fará que seja para melhor." (Carta XXVI - Ao Marquês de Niza - Século XVII)

Em (13), a locução adverbial estabelece uma sequência de tempo com "ás quartas e quintas" e "á sexta feira", abordando o que ocorre em cada grupo de dias da semana. Em (14), há caso semelhante por meio de "em 13 de dezembro", o qual designa uma sequência juntamente à locução "em 15". 
(d)

Introdutor de assunto: o adverbial marca o início de um (novo) assunto.

"Muitas vezes penso, Irmãos, que estes Gentios esperam que seja o nosso sangue o fundamento desta nova egreja, e por isso vinde, trazei-o para que Christo Nosso Senhor se digne de aceital-o." (Carta XV - Século XVI)

"Esta semana deve de haver conferência: no correio que vem parece que poderemos escrever com alguma certeza, posto que ficamos com maiores esperanças que nunca, e eu com o coração muito desassombrado, porque para a guerra ou para a paz sempre é melhor serrar de cima." (Carta XLI - Ao Marquês de Niza - Século XVII)

Em (15), "muitas vezes" introduz um assunto, bem como em (16) "esta semana" tem o mesmo papel no discurso. Ambos iniciam o discurso, tendo, assim, essa função. Vale dizer, contudo, que locuções que não introduzem o texto podem ter a mesma função ao, por exemplo, iniciarem um novo assunto. Em nossa amostra, não tivemos ocorrências com essas características no século XVI, apenas no XVII. No entanto, nesses casos, o adverbial assumia outras funções no discurso ao, por exemplo, estabelecer uma sequência temporal, o que não permitia que fosse classificado apenas como "introdutor de assunto". Assumimos, nesses casos, a nomenclatura "função mista".

(e)

Função mista: a locução possui mais de um papel discursivo, tal como introdutor de assunto e sequência temporal.

"Na noite, de sábado tinha chegado de Amsterdam Mr. de Ia Tulherie, e logo no domingo- veio ver o senhor Embaixador; e ainda que estão tão amigos que não guardam correspondências nas visitas, a de ontem tocava mais ao senhor Embaixador, e assim nos pareceu misteriosa." (Carta XX - Ao Marquês de Niza - Século XVII)

Em (17), a locução adverbial, além de introduzir um assunto, estabelece uma sequência temporal com "no domingo", tendo, assim, duas funções, o que denominamos de "Mista". 
A partir das funções apresentadas, efetuamos um cruzamento estatístico entre as posições do adverbial e seus papéis no discurso, assim como demonstra a tabela 3:

Tabela 3 - CruZamento entre a ordenaÇão das locuÇões temporais e suas FUNÇÕES DISCURSIVAS NO SÉCULO XVI

\begin{tabular}{l|l|l|l|l|l}
\hline \multirow{2}{*}{ FunÇão } & \multicolumn{4}{|l|}{ ORDENAÇÃo DO ADVERBIAL } & \multirow{2}{*}{ TOTAL } \\
\cline { 2 - 5 } & $\begin{array}{l}\text { MARGEM } \\
\text { ESQUERDA }\end{array}$ & $\begin{array}{l}\text { MARGEM } \\
\text { DIREITA }\end{array}$ & $\begin{array}{l}\text { PRÉ-VERBAL } \\
\text { NÃO INICIAL }\end{array}$ & $\begin{array}{l}\text { PÓS-VERBAL } \\
\text { NÃO FINAL }\end{array}$ & \\
\hline $\begin{array}{l}\text { Atribuidor de } \\
\text { coordenadas } \\
\text { temporais }\end{array}$ & 29 & 46 & 4 & 19 & 98 \\
\hline $\begin{array}{l}\text { Introdutor de } \\
\text { assunto }\end{array}$ & 14 & -- & -- & $19,39 \%$ & $100 \%$ \\
\hline Retomada & $100 \%$ & -- & -- & -- & 14 \\
anafórica & $33,33 \%$ & $66,67 \%$ & -- & -- & $100 \%$ \\
\hline $\begin{array}{l}\text { Sequência } \\
\text { temporal }\end{array}$ & 18 & 12 & -- & - & 3 \\
\hline Função mista & $48,65 \%$ & $32,43 \%$ & -- & $18,92 \%$ & $100 \%$ \\
\hline Total & -- & -- & -- & -- & -- \\
\hline
\end{tabular}

Fonte: Elaborado pelos autores.

Segundo nossa hipótese, fundamentada em Paiva (2008), adverbiais com função mais ligadas ao contexto em que se inserem tenderiam às posições à esquerda; aqueles que estivessem mais restritos à cláusula tenderiam à direita. Ao observamos a tabela 3 , percebemos que os dados com papel de apenas atribuir coordenadas temporais ocorreram principalmente em posições pós-verbais, sobretudo em margem direita (46,94\%), confirmando o que havíamos postulado. Os demais casos, 
porém, confirmaram parcialmente nossa hipótese. As locuções com função de introduzir um assunto, por exemplo, ocorreram apenas à esquerda, mais especificamente em contexto marginal, totalizando $100 \%$ dos dados, confirmando nossa expectativa. Ao analisarmos os dados com papel de retomada anafórica, contudo, percebemos que $66,7 \%$ estiveram em contexto pós-verbal, contrariando o que esperávamos. Os casos de sequência temporal ocorreram prioritariamente em margem esquerda $(48,65 \%)$, mas, caso comparemos os dois contextos mais gerais - antes e depois do verbo - perceberemos que a maior parte dos dados está sob paradigma pós-verbal $(32,43 \%$ em margem direita e $18,92 \%$ em outras posições pós-verbais), refutando nossa hipótese.

A seguir apresentamos a tabela com os resultados do século XVII:

Tabela 4 - CRUZamento entre ordenaÇão e funÇÃo discursiva das locuÇões NO SÉCULO XVII

\begin{tabular}{|c|c|c|c|c|c|}
\hline \multirow{2}{*}{$\begin{array}{l}\text { FUNÇÃO } \\
\text { DISCURSIVA }\end{array}$} & \multicolumn{4}{|c|}{ ORDENAÇÃO DO ADVERBIAL } & \multirow[t]{2}{*}{ Total } \\
\hline & $\begin{array}{l}\text { MARGEM } \\
\text { ESQUERDA }\end{array}$ & $\begin{array}{l}\text { MARGEM } \\
\text { DiREITA }\end{array}$ & $\begin{array}{l}\text { PRÉ-VERBAL } \\
\text { NÃO INICIAL }\end{array}$ & $\begin{array}{l}\text { PÓS-VERBAL } \\
\text { NÃO FINAL }\end{array}$ & \\
\hline $\begin{array}{l}\text { Atribuidor de } \\
\text { coordenadas } \\
\text { temporais }\end{array}$ & $\begin{array}{l}25 \\
26,60 \%\end{array}$ & $\begin{array}{l}43 \\
45,74 \%\end{array}$ & $\begin{array}{l}5 \\
5,32 \%\end{array}$ & $\begin{array}{l}21 \\
22,34 \%\end{array}$ & $\begin{array}{l}94 \\
100 \%\end{array}$ \\
\hline $\begin{array}{l}\text { Introdutor de } \\
\text { assunto }\end{array}$ & $\begin{array}{l}13 \\
100 \%\end{array}$ & $\begin{array}{l}-- \\
--\end{array}$ & - & $\begin{array}{l}-- \\
--\end{array}$ & $\begin{array}{l}13 \\
100 \%\end{array}$ \\
\hline $\begin{array}{l}\text { Retomada } \\
\text { anafórica }\end{array}$ & $\begin{array}{l}1 \\
33,33 \%\end{array}$ & $\begin{array}{l}2 \\
66,67 \% \\
\end{array}$ & - & -- & $\begin{array}{l}3 \\
100 \% \\
\end{array}$ \\
\hline $\begin{array}{l}\text { Sequência } \\
\text { temporal }\end{array}$ & $\begin{array}{l}13 \\
39,39 \%\end{array}$ & $\begin{array}{l}15 \\
45,45 \% \\
\end{array}$ & $\begin{array}{l}1 \\
3,03 \% \\
\end{array}$ & $\begin{array}{l}4 \\
12,12 \%\end{array}$ & $\begin{array}{l}33 \\
100 \% \\
\end{array}$ \\
\hline Função mista & $\begin{array}{l}7 \\
100 \%\end{array}$ & $\begin{array}{l}-- \\
--\end{array}$ & $\begin{array}{l}-- \\
--\end{array}$ & $\begin{array}{l}-- \\
--\end{array}$ & $\begin{array}{l}7 \\
100 \%\end{array}$ \\
\hline
\end{tabular}




\begin{tabular}{l|l|l|l|l|l}
\hline \multirow{2}{*}{ FUNÇão } & \multicolumn{3}{l|}{ ORDENAÇ̃̃o DO ADVERBAL } & \multirow{2}{*}{ TOTAL } \\
\cline { 2 - 5 } DISCURSIVA & $\begin{array}{l}\text { MARGEM } \\
\text { ESQUERDA }\end{array}$ & $\begin{array}{l}\text { MARGEM } \\
\text { DIREITA }\end{array}$ & $\begin{array}{l}\text { PRÉ-VERBAL } \\
\text { NÃO INICIAL }\end{array}$ & $\begin{array}{l}\text { PÓS-VERBAL } \\
\text { NÃO FINAL }\end{array}$ & \\
\hline TotAL & 59 & 60 & 6 & 25 & 150 \\
& $39,33 \%$ & $40 \%$ & $4 \%$ & $16,67 \%$ & $100 \%$ \\
\hline
\end{tabular}

Fonte: Elaborado pelos autores.

$\mathrm{Na}$ tabela acima, observamos maior quantitativo de dados em posições posteriores ao verbo quando a função do adverbial é apenas atribuir tempo ao evento (45,74\% em margem direita e $22,34 \%$ em outras ordenações), o que confirma nossa hipótese de que por ter um papel textual ligado mais à cláusula, esse grupo de advérbios ocupará o posicionamento pós-verbal. As locuções adverbiais com função de introduzir um assunto, retomar algo, estabelecer uma sequência temporal ou aquelas possuidoras de duas dessas funções tenderiam ao posicionamento pré-verbal, segundo o que postulamos. Ao analisarmos a tabela 4, no entanto, percebemos que nossa hipótese não foi totalmente confirmada. Obtivemos $100 \%$ dos dados introdutórios de novo assunto em margem esquerda, além de $100 \%$ dos que possuíam função mista na mesma posição, confirmando nossa expectativa. Nos adverbiais com demais funções, contudo, obtivemos resultados distintos: ao retomar algo já proferido no discurso, as locuções ocorreram mais em posição pós-verbal $(66,7 \%)$, assim como aquelas com função de sequência temporal $(45,45 \%$ em margem direita e $12,12 \%$ outras posições após o verbo), refutando nosso postulado.

Ao comparamos ambos os resultados com outros estudos sobre o comportamento de locuções temporais na história do português, percebemos que do século XVI ao português contemporâneo houve uma manutenção do posicionamento predominantemente pós-verbal em relação às coordenadas temporais e da ordenação pré-verbal para os circunstanciadores com função de introduzir assunto (ILOGTI DE SÁ, 2009; MACHADO, 2012); as locuções com função mista não ocorreram no século XVI, mas ocorreram nos séculos XVII e em outros estudos sobre sincronias posteriores (SOARES, 2012; CASTANHEIRA; CEZARIO, 2014) em posição predominantemente pré-verbal. 
As locuções com função anafórica ocorreram mais em posições pós-verbais nas duas sincronias que apresentamos, mas obtiveram equilibrada distribuição em Machado (2012) numa análise dos séculos XVIII e XIX. Em Castanheira e Cezario (2014) e Ilogti de Sá (2009), com estudos sobre, respectivamente, o século XIX e o português contemporâneo, elas já estiveram predominantemente na posição préverbal. Em relação às locuções que estabelecem sequências temporais, notamos que houve uma tendência pós-verbal nos séculos XVI e XVII. Ao observarmos outras sincronias, no entanto, observamos que a locução tende a posições pré-verbais, especialmente a margem esquerda, quando possui papel discursivo anafórico. Tanto em Ilogti de Sá (2009), como em Machado (2012) e Soares (2012), a tendência foi a mesma ao observarem sincronias seguintes do português. Provavelmente os usos anafóricos das cartas dos séculos mais atuais apresentam um valor mais contrastivo com informações do discurso antecedente às orações em análise e, portanto, as locuções ocorrem mais nas posições mais à esquerda do verbo, o que explica os resultados díspares.

\subsection{ORDEM ORACIONAL}

Essa categoria motivadora para a locução adverbial possui cunho sintático. A discussão envolve em que medida a ordem oracional, diante de algumas possibilidades de ocorrência elencadas e já usadas em outros trabalhos, sobretudo Castanheira e Cezario (2014), é determinante para o posicionamento do adverbial no texto.

(a)

$\mathrm{SV}^{2}$ : o sujeito ocorre antes do verbo e está presente formalmente.

E $\underline{\text { uma índia }}{ }^{3}$ destas doutrinadas se levantou uma noite a pregar por estas ruas de S. Vicente (Carta VII - Século XVI)

Já V. Ex.a vê o ânimo que isto causará nos armadores das fragatas, e quanto poderá esfriar a resolução dos que estavam determinados a fazer paz conosco, que eram os fundamentos sólidos sobre que as esperanças de acomodamento estribavam até agora. (Carta XXXIV - Ao Marquês de Niza - Século XVII) 
(b)

VS: o verbo ocorre antes do sujeito.

(20)

Ahi se reúnem aos sabbados os habitantes de duas ou três villas, entre os quaes demora a dita egreja; pelo que está o seu tanto exposta aos perigos da guerra que repetidas vezes movem os índios que são innumeraveis contra os Christãos."(Carta XVII - Século XVI)

"E neste mesmo tempo chegou uma carta de S. M., em que diz que aqueles homens são da jurisdição eclesiástica, em que êle não tem poder, e que se lhe não torne a falar naquela matéria." (Carta XX - Ao Marquês de Niza - Século XVII)

(c)

V: o sujeito não está presente formalmente.

“A elle não tenho confessado, porque de todo tinha já estragado o juizo, em tanto que as primeiras praticas que lhe fazia, tenho para mim que as não entendia e ainda agora pouco mais entende." (Carta III - Século $\mathrm{XVI})$

"E neste mesmo tempo, para que V Ex. mais se admire, cuidam em Portugal que em Castela se apresta armada contra Lisboa, e que Laganez entrará com exército por Alentejo; e, quando não têm com que acudir bastantemente a uma destas partes, há quem aconselhe que nos dividamos em tantas outras. (Carta XLVIII - Ao Marquês de Niza Século XVII)

(d)

S(PR)V: o sujeito ocorre formalmente como pronome relativo.

"Porque havia muitas almas que não se haviam confessado trinta ou quarenta annos e estavam em peccado mortal, e isto publicamente." (Carta II - Século XVI) 
(25)

"Esta semana chegou aqui um mercador de Viana, tomado na altura da Baía, que nos confirmou as novas que escrevi a V. Ex.a a semana passada, e acrescentou que até os 15 ou 16 de Dezembro avistaria a nossa armada a costa de Pernambuco, porque três dias antes fora vista por uma fragata holandesa em distância só de sessenta léguas, correndo rijamente os nordestes, que é a monção que naqueles meses nunca fal$\underline{\text { ta}}$, donde se colhe que em quarenta e dois dias chegou a armada desde a ilha da Madeira a Pernambuco, que, quando fora uma só caravela, era boa viagem. (Carta XXIII - Ao Marquês de Niza - Século XVII)

A partir da análise dos dados, obtivemos a seguinte tabela para o século XVI:

Tabela 5 - CRuZamento entre a ordenaÇÃo das locuções temporais E aS ORDENS DA ORAÇÃO NO SÉCULO XVI

\begin{tabular}{|c|c|c|c|c|c|}
\hline \multirow{2}{*}{$\begin{array}{l}\text { ORDEM dA } \\
\text { OraÇÃo }\end{array}$} & \multicolumn{4}{|c|}{ Posição DA LOCUÇão } & \multirow[t]{2}{*}{ TOTAL } \\
\hline & $\begin{array}{l}\text { MARGEM } \\
\text { ESQUERDA }\end{array}$ & $\begin{array}{l}\text { MARGEM } \\
\text { DIREITA }\end{array}$ & $\begin{array}{l}\text { PRÉ-VERBAL } \\
\text { NÃO INICIAL }\end{array}$ & $\begin{array}{l}\text { PÓS-VERBAL } \\
\text { NÃO FINAL }\end{array}$ & \\
\hline SV & $\begin{array}{l}1 \\
6,67 \% \\
\end{array}$ & $\begin{array}{l}10 \\
66,67 \% \\
\end{array}$ & $\begin{array}{l}2 \\
13,33 \% \\
\end{array}$ & $\begin{array}{l}2 \\
13,33 \% \\
\end{array}$ & $\begin{array}{l}15 \\
100 \% \\
\end{array}$ \\
\hline VS & $\begin{array}{l}4 \\
40 \%\end{array}$ & $\begin{array}{l}3 \\
30 \%\end{array}$ & $\begin{array}{l}1 \\
10 \%\end{array}$ & $\begin{array}{l}2 \\
20 \% \\
\end{array}$ & $\begin{array}{l}10 \\
100 \%\end{array}$ \\
\hline $\mathbf{V}$ & $\begin{array}{l}57 \\
45,97 \%\end{array}$ & $\begin{array}{l}44 \\
35,48 \%\end{array}$ & $\begin{array}{l}1 \\
0,81 \%\end{array}$ & $\begin{array}{l}22 \\
17,74 \% \\
\end{array}$ & $\begin{array}{l}124 \\
100 \%\end{array}$ \\
\hline $\mathbf{S}(\mathbf{P R}) \mathbf{V}$ & $\begin{array}{l}- \\
- \\
-\end{array}$ & $\begin{array}{l}3 \\
100 \% \\
\end{array}$ & - & - & $\begin{array}{l}3 \\
100 \% \\
\end{array}$ \\
\hline Total & $\begin{array}{l}62 \\
40,79 \%\end{array}$ & $\begin{array}{l}60 \\
39,47 \%\end{array}$ & $\begin{array}{l}4 \\
2,63 \%\end{array}$ & $\begin{array}{l}26 \\
17,11 \%\end{array}$ & $\begin{array}{l}152 \\
100 \%\end{array}$ \\
\hline
\end{tabular}

Fonte: Elaborado pelos autores. 
De acordo com nossa hipótese, as locuções tenderiam à margem esquerda em casos de ordem oracional VS e ocorreriam menos nessa posição nas demais ( $\mathrm{SV}, \mathrm{V}, \mathrm{S}(\mathrm{PR}) \mathrm{V})$. A partir da tabela 5, podemos afirmar que, diante da ausência de sujeito iniciando a oração, a locução tendeu a ocorrer mais em margem esquerda (40\%), ocupando a posição do tópico. Abordagens formais já preveem esse resultado devido ao equilíbrio sintático, mas o fato de haver uma ocorrência mesmo em casos SV demonstra que questões funcionais, como a função discursiva, podem influenciar nesse aspecto.

Diante do preenchimento formal do sujeito, como sintagma ou como pronome relativo, houve mais locuções em posições pós-verbais, tanto na ordem SV $(66,67 \%$ em margem direita e $13,33 \%$ em outras posições pós-verbais), como na ordem $\mathrm{S}(\mathrm{PR}) \mathrm{V}$ (100\% em margem direita). Quando tivemos ordem oracional V, tivemos maior quantitativo de dados após o verbo do que antes (35,48\% em margem direita e 17,74\% em outras posições pós-verbais), confirmando nossa hipótese.

Apresentaremos agora o cruzamento estatístico entre as posições da locução e as ordens da oração no século XVII:

TABela 6 - CRUZAmento ENTRE A ORDENAÇÃO DAS loCUÇÕES DE TEMPO E AS ORDENS DA ORAÇ̃̃o NO SÉCULO XVII

\begin{tabular}{|c|c|c|c|c|c|}
\hline \multirow{2}{*}{$\begin{array}{l}\text { ORDEM DA } \\
\text { ORAÇÃOO }\end{array}$} & \multicolumn{4}{|c|}{ PoSIÇÃO DA LOCUÇÃO } & \multirow[t]{2}{*}{ TOTAL } \\
\hline & $\begin{array}{l}\text { MARGEM } \\
\text { ESQUERDA }\end{array}$ & $\begin{array}{l}\text { MARGEM } \\
\text { DIREITA }\end{array}$ & $\begin{array}{l}\text { PRÉ-VERBAL } \\
\text { NÃO INICIAL }\end{array}$ & $\begin{array}{l}\text { PÓS-VERBAL } \\
\text { NÃO FINAL }\end{array}$ & \\
\hline SV & $\begin{array}{l}2 \\
13,33 \%\end{array}$ & $\begin{array}{l}8 \\
53,33 \%\end{array}$ & $\begin{array}{l}4 \\
26,67 \%\end{array}$ & $\begin{array}{l}1 \\
6,67 \%\end{array}$ & $\begin{array}{l}15 \\
100 \%\end{array}$ \\
\hline VS & $\begin{array}{l}15 \\
53,57 \%\end{array}$ & $\begin{array}{l}6 \\
21,43 \%\end{array}$ & $\begin{array}{l}1 \\
3,57 \%\end{array}$ & $\begin{array}{l}6 \\
21,43 \%\end{array}$ & $\begin{array}{l}28 \\
100 \%\end{array}$ \\
\hline $\mathbf{V}$ & $\begin{array}{l}39 \\
37,86 \%\end{array}$ & $\begin{array}{l}46 \\
44,66 \%\end{array}$ & $\begin{array}{l}1 \\
0,97 \%\end{array}$ & $\begin{array}{l}17 \\
16,50 \%\end{array}$ & $\begin{array}{l}103 \\
100 \%\end{array}$ \\
\hline
\end{tabular}




\begin{tabular}{l|l|l|l|l|l}
\hline \multirow{2}{*}{$\begin{array}{l}\text { ORDEM DA } \\
\text { ORAÇÃo }\end{array}$} & \multicolumn{4}{l|}{ POSIÇ̃̃o DA LOCUÇÃo } & \multirow{2}{*}{ TOtAL } \\
\cline { 2 - 5 } & $\begin{array}{l}\text { MARGEM } \\
\text { ESQUERDA }\end{array}$ & $\begin{array}{l}\text { MARGEM } \\
\text { DIREITA }\end{array}$ & $\begin{array}{l}\text { PRÉ-VERBAL } \\
\text { NÃO INICIAL }\end{array}$ & $\begin{array}{l}\text { PóS-VERBAL } \\
\text { NÃO FINAL }\end{array}$ & \\
\hline S(PR)V & 3 & -- & -- & 1 & 4 \\
& $75 \%$ & -- & -- & $25 \%$ & $100 \%$ \\
\hline TOTAL & 59 & 60 & 6 & 25 & 150 \\
& $39,33 \%$ & $40 \%$ & $4 \%$ & $16,67 \%$ & $100 \%$ \\
\hline
\end{tabular}

Fonte: Elaborado pelos autores.

A partir da tabela acima, percebemos que diante da forma oracional VS, a maioria dos dados estava em margem esquerda (53,57\%), assim como postulara nossa hipótese. Trabalhos como Duarte (2007) e Votre e Santos (1984) explicam que os advérbios vêm para a posição inicial quando o sujeito está na ordem VS. Haveria, assim, uma espécie de equilíbrio sintático, havendo constituindo antes e depois do verbo. Nossos resultados, contudo, apontam que houve 13,3\% de locuções adverbiais na posição inicial, mesmo com o sujeito antes do verbo; apontam também que há $21,43 \%$ de dados na margem direita com sujeito na ordem VS. Sendo assim, a hipótese do equilíbrio sintático é fraca. Não é por uma questão de equilíbrio sintático que os usuários colocam as locuções numa ou noutra posição, mas por questões mais discursivas, como o fato de essas locuções terem um papel importante para estabelecer ênfase ou algum tipo de ligação com o discurso anterior quando estão na posição inicial.

Em relação à ordem $\mathrm{SV}$, a maior parte das locuções ocorreu em posições pós-verbais $(53,33 \%$ em margem direita e $6,67 \%$ em outras pós-verbais), assim como em V (44,66\% em margem direita e 16,5\% em pós-verbais não finais), confirmando nossa hipótese.

Ao compararmos esses resultados com outras sincronias, notamos que as mesmas tendências existentes em relação à SV, VS e V nos séculos XVI e XVII, ocorreram em Machado (2012) e Soares (2012), demonstrando possível estabilidade nesse aspecto na história do português. Já em relação à ordem $\mathrm{S}(\mathrm{PR}) \mathrm{V}$, o século XVII apresentou comportamento heterogêneo aos demais séculos, inclusive o XVI. Isso 
demonstra a possível necessidade de investigar mais o século XVII por meio de outros textos que podem, ou não, pertencer a esse gênero textual.

\section{Conclusão}

Nossa análise demonstrou que a ordenação da locução adverbial de tempo em cartas jesuíticas dos séculos XVI e XVII pode ser motivada tanto pela ordem da oração em que está inserida, como pela função discursivo-textual que o adverbial estabelece.

As hipóteses apresentadas foram parcialmente confirmadas, apontando a necessidade de outras investigações para o comportamento da locução temporal em ambas as sincronias, sobretudo no século XVII. Além disso, há, provavelmente, a necessidade de observar outros gêneros textuais para designar em que medida esse fator pode ser determinante na análise desses séculos.

Ao compararmos nossos resultados com outras sincronias, percebemos que houve discretas disparidades entre os séculos aqui estudados. Ao observarmos sincronias posteriores, no entanto, a diferença é significativa, principalmente em relação à ordenação no gênero carta, que nos séculos XVIII e XIX tende à margem direita e nas sincronias aqui observadas obteve equilíbrio entre as posições marginais.

A pesquisa contribuiu para compreensão de alguns aspectos relativos à relação entre sintaxe e fatores discursivo-pragmáticos no uso de locuções adverbiais temporais na história da língua portuguesa, mais particularmente no período compreendido pelos séculos XVI e XVII. Além disso, contribui para o entendimento do papel das locuções adverbiais num gênero em particular: as cartas jesuíticas.

THE WORD ORDER OF TIME ADVERBIAL PHRASES IN THE $16^{\text {TH }} \mathrm{C}$ AND $17^{\text {тн }} \mathrm{C}$ JESUIT LETTERS

\section{ABSTRACT}

In this paper, we discuss word order trends of adverbial phrases of time in letters written by Jesuits in the $16^{\text {th }} \mathrm{C}$ and $17^{\text {th }} \mathrm{C}$. Also, we present some of the reasons for these trends through a structural and discoursive-pragmatic analysis. The 
North American functionalism theory is the theoretical framework of the research, once we consider the relationship between form and function in speech relevant. We seek to verify standardized time adverbial word order, analyze factors that motivate different positions for these locutions in the clause and compare the results with prior historical moments of Portuguese to assess in which extent they can indicate linguistic change.

Keywords: time adverbial phrases, functionalism, word order, Portuguese language history.

\section{LA ORDENACIÓN DE LAS LOCUCIONES ADVERBIALES DE TIEMPO EN CARTAS JESUÍTICAS DE LOS SIGLOS XVI Y XVII}

\section{RESUMEN}

En este trabajo, discutimos las tendencias de ordenación de las locuciones adverbiales de tiempo en cartas escritas por jesuitas durante los siglos XVI y XVII, también presentamos algunas de las motivaciones que llevaron a su posición en la oración. Para eso, nos basamos en un análisis estructural y discursivo pragmático. Seguimos los supuestos teóricos del funcionalismo norteamericano, considerando pertinente la relación entre forma y función en el discurso. Buscamos (a) verificar padrones de posición en la oración, (b) analizar factores que justifican las distintas posiciones de esas locuciones y (c) comparar los resultados con otras sincronías del portugués, evaluando en qué medida ellos pueden denunciar indicios de transformación lingüística.

PalaVras-clave: Locuciones adverbiales de tiempo, Funcionalismo, Ordenación, Historia de la lengua portuguesa.

\section{NOTAS}

1 O termo "adverbial" é usado para englobar os advérbios e as locuções adverbiais (OLIVEIRA; CEZARIO, 2012).

2 Consideramos nas ordens SV e VS que o sujeito pode vir representado como sintagma nominal ou oracional.

3 Foram destacados em sublinhado nessa seção partes importantes para a análise, como o sujeito e o verbo. 


\section{REFERÊNCIAS}

ANDRADE, Q. Ordenação das locuções adverbiais de tempo em editoriais. 2005. Dissertação (Mestrado em Linguística) - Faculdade de Letras, Universidade Federal do Rio de Janeiro, Rio de Janeiro, 2005,

AZEVEDO, J. L. Cartas do Padre António Vieira. Coimbra: Imprensa da Universidade, 1925.

BAKHTIN, M. Os gêneros do discurso. In: BAKHTIN, M. Estética da criação verbal. São Paulo: Martins Fontes, 2003.

BYBEE, J. Language, usage and cognition. New York: Cambridge University Press, 2010.

CARTAS avulsas 1550 - 1568. Rio de Janeiro: Officina Industrial Graphica, 1931.

CASTANHEIRA, D.; CEZARIO, M. M. Locuções adverbiais de tempo em cartas oficias do século XIX: motivações para a ordenação. Soletras, Rio de Janeiro, v. 28, n. 2, p. 41-59, 2014.

CEZARIO, M. M.; FURTADO, M. A. Linguística Centrada no Uso: uma homenagem a Mário Martelotta. Rio de Janeiro: Mauad-X, 2013.

COSTA NUNES, J. O. Mente de antigamente. 2014. Tese (Doutorado em Linguística) - Faculdade de Letras, Universidade Federal do Rio de Janeiro, Rio de Janeiro, 2014.

DUARTE, M. E. L. Aspectos inovadores e conservadores na escrita padrão. Linguística, Rio de Janeiro, v. 3, n.1, 2007.

ILOGTI DE SÁ, E. C. Ordenação de locuções de tempo e aspecto em textos jornalísticos: uma abordagem funcionalista. 2009. Dissertação (Mestrado em Linguística) - Faculdade de Letras, Universidade Federal do Rio de Janeiro, Rio de Janeiro, 2009.

KEMMER, S.; BARLOW, M. Introduction: a usage-based conception of language. In: BARLOW, M.; KEMMER, S. (Ed.). Usage based models of language. Stanford, California: CSLI Publications, 1999.

LONDOÑO, F. T. Escrevendo cartas. Jesuítas, escrita e missão no século XVI. Revista Brasileira de História, São Paulo, n. 43, 2002.

MACHADO, N. I. P. As locuções adverbiais temporais e aspectuais nos séculos XVIII e XIX do Português: um estudo da ordem. 2012. Dissertação (Mestrado em Linguística) Faculdade de Letras, Universidade Federal do Rio de Janeiro, Rio de Janeiro, 2012. 
MARCUSCHI, L. A. Produção textual, análise de gêneros e compreensão. São Paulo: Parábola, 2012.

. Gêneros textuais: definição e funcionalidade. In: DIONÍSIO, A. P.; MACHADO, A. R.; BEZERRA, M. A. (Org.) Gêneros textuais e ensino. Rio de Janeiro: Editora Lucerna, 2002.

MARTELOTTA, M. E. T. Os circunstanciadores temporais e sua ordenação: uma visão funcional. 1994. 250 f. Tese (Doutorado em Linguística) Faculdade de Letras, Universidade Federal do Rio de Janeiro, Rio de Janeiro, 1994.

.Ordenação dos advérbios bem e mal no português escrito: uma abordagem histórica. Rio de Janeiro: UFRJ (Relatório final apresentado ao CNPq), 2004.

. Mudança Linguística: uma abordagem baseada no uso. Rio de Janeiro: Cortez, 2011.

.; VLCEK, N. Advérbios qualitativos em -mente em cartas de jornais do século XIX. Linguística: Revista do Programa de Pós-Graduação em Linguística da UFRJ. Rio de Janeiro: UFRJ, junho de 2006.

OLIVEIRA, M. R.; CEZARIO, M. M. Adverbiais: aspectos gramaticais e pressões discursivas. Niterói: Editora da UFF, 2012.

PAIVA, M. da C. de. Ordem não-marcada de circunstanciais locativos e temporais. In: VOTRE, S.; RONCARATI, C. (Org.). Anthony Julius Naro e a Linguística no Brasil: uma homenagem acadêmica. Rio de Janeiro: 7 Letras, 2008.

SOARES, B. G. Ordenação de locuções adverbiais temporais iniciadas pela preposição em (e contrações) em textos jornalísticos. 2012. Dissertação (Mestrado em Linguística) - Faculdade de Letras, Universidade Federal do Rio de Janeiro, Rio de Janeiro, 2012.

TRAUGOTT, E.; TROUSDALE, G. Construcionalization and Constructional Changes. Oxford: University Press, 2013.

VOTRE, S. J.; SANTOS, E. Colocação do Advérbio na fala e na escrita: uma análise sociolingüistica. Relatório final do Projeto Análise Lingüísticopedagógica das diferenças sintáticas entre fala e escrita em alunos de $1^{\circ}$ grau. Rio de Janeiro: Universidade Gama Filho. 1984.

Submetido em 15 de maio de 2015.

Aceito em 08 de setembro de 2016.

Publicado em 23 de novembro de 2016. 